\title{
Erratum to: Biomass HotSpot distribution model and spatial interaction of two exploited species of horse mackerel in the south-central Mediterranean Sea
}

\author{
Giacomo Milisenda (1) - Germana Garofalo - Samia Fezzani - Okbi Rjeibi • \\ Othman Jarboui • Bachra Chemmam • Luca Ceriola • Angelo Bonanno • \\ Simona Genovese - Gualtiero Basilone - Roberta Mifsud - Valentina Lauria • \\ Michele Gristina $\cdot$ Francesco Colloca $\cdot$ Fabio Fiorentino
}

Published online: 4 October 2017

(C) Springer International Publishing AG 2017

\section{Erratum to: Hydrobiologia \\ DOI 10.1007/s10750-017-3336-7}

Due to an unfortunate turn of events, the first- and surnames of all authors were transposed in the original publication. The correct representation of the authors and their affiliations are listed above and below and should be treated as definitive.
The online version of the original article can be found under doi:10.1007/s10750-017-3336-7.

G. Milisenda ( $₫) \cdot$ G. Garofalo · V. Lauria •

M. Gristina · F. Colloca · F. Fiorentino

CNR-IAMC, sede secondaria di Mazara del Vallo, Via

Luigi Vaccara 61, 91026 Mazara Del Vallo, Italy

e-mail: giacomo.milisenda@gmail.com

S. Fezzani · O. Rjeibi · B. Chemmam

INSTM - Centre de La Goulette, 2060 La Goulette,

Tunisia

O. Jarboui

Institut National des Sciences et Technologies de la Mer

(INSTM) - centre de Sfax, 3018 Sfax, Tunisia

\begin{abstract}
L. Ceriola
FAO MedSudMed, Viale delle Terme di Caracalla,

00153 Rome, Italy
\end{abstract}

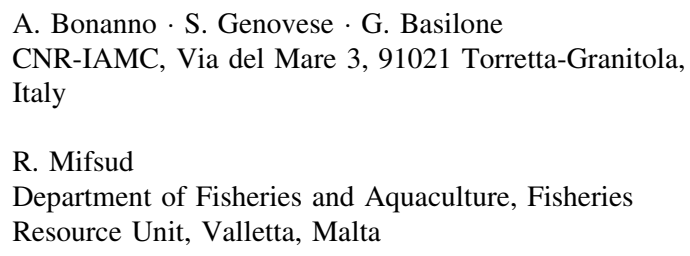

A. Bonanno $\cdot$ S. Genovese $\cdot$ G. Basilone

CNR-IAMC, Via del Mare 3, 91021 Torretta-Granitola, Italy

R. Mifsud

Department of Fisheries and Aquaculture, Fisheries

Resource Unit, Valletta, Malta 